\title{
Migración internacional, remesas y desarrollo del mito a la realidad
}

\author{
Rodolfo García Zamora*
}

Actualmente en América Latina las remesas sobrepasan los 60 mil millones de dólares anuales. Este flujo representa uno de los principales rubros de transferencias corrientes en la Balanza de Pagos, superando en muchos casos el ingreso derivado de los principales rubros de exportación y la inversión extranjera directa, a la vez que son muy superiores a los recursos derivados de la cooperación internacional para el desarrollo. Estos volúmenes que han alcanzado las remesas, hacen que ellas se vuelvan no sólo visibles a los ojos de la sociedad, sino que las convierten en un importante tema de debate social, político y académico, en función de sus aparentes potencialidades como posible fuente de financiamiento del desarrollo local y regional (CANALES, A., 2008).

En el contexto anterior, Alejandro Canales destaca como diversos organismos internacionales (FMI, BID-FOMIN, UNCTAD, Banco Mundial, entre otros) junto con gobiernos nacionales y locales enfocan su atención en las remesas como instrumento preferencial que podría contribuir a la reducción de la pobreza y promover el desarrollo de los países de origen de la migración internacional. En contraposición a este discurso predominante, diversos organismos de la sociedad civil y no pocos académicos cuestionan estos enfoques, aduciendo que en esencia las remesas son transferencias privadas entre particulares, que por lo mismo, no pueden sustituir la responsabilidad del Estado y la acción del mercado en la promoción del desarrollo económico y el bienestar de la población.

Para el mismo autor, el debate se ha centrado preferentemente en torno a CÓMO las remesas podrían promover un proceso de desarrollo económico en las regiones de origen de la migración, dejando amplios vacíos en torno al POR QUÉ las remesas podrían tener tal impacto (o no tenerlo, según sea el caso). Canales, desde la macroeconomía propone un modelo de análisis de la relación remesas-desarrollo que permite entender y evaluar los distintos impactos de las remesas familiares en función del carácter y modalidad que ellas asuman, así como de su significado y comportamiento específico como categoría económica. El supuesto detrás de ésta propuesta es muy sencillo: el impacto de las remesas depende directamente de cómo ellas se incorporan a la estructura económica

* Rodolfo García Zamora - Doctorado en Estudios del Desarrollo/Universidad Autónoma de Zacatecas, México. 
de cada sociedad, es decir, de cuál es el carácter y la lógica que define su comportamiento macroeconómico. Canales (2008) sintetiza su cuestionamiento al enfoque que sobrevalora el impacto de las remesas sobre el desarrollo de la siguiente manera: ¿Por qué las remesas deberían tener algún impacto sobre la dinámica de desarrollo de las economías del Tercer Mundo?

Para él, las remesas son una transferencia de recursos privados, el punto en discusión es definir su carácter y significado económico (además de sus significados sociales y culturales). Como flujo de transferencias, las remesas tienen un impacto en la dinámica macroeconómica y microeconómica de los países receptores. No obstante, este impacto dependerá directamente del significado económico que ellas asuman en cada momento.

Desde la macroeconomía considera que se puede valorar su impacto si diferenciamos entre remesas salariales (familiares) y las remesas de capital (productivas).

a) Las primeras, corresponden a transferencias directas para su uso familiar, ya sea para el consumo (remesa salario) para ser ahorradas en función de un consumo familiar futuro, o para casos de emergencias familiares, o bien para sufragar los gastos de la reproducción de los usos y costumbres familiares que implican la reproducción de las relaciones culturales.

b) Las remesas productivas en cambio, corresponden a diversas formas de inversión privada o social, que no pasan por el presupuesto familiar. Se trata de transferencias específicas con fines de inversión, frecuentemente pequeños comercios o micro-proyectos productivos.

La diferencia conceptual anterior permite captar el diferente uso e impacto de las remesas en las comunidades de origen de los migrantes. Por ejemplo, en el caso de las remesas salariales, ellas contribuyen a sustentar el balance ingreso-gasto de los hogares. Por ese medio, sus impactos se dan en dos sentidos y complementarios:

a) Por un lado, por su aporte al consumo familiar, contribuyen a elevar el nivel de vida y bienestar de los hogares receptores, a la vez que inciden en la dinámica de las desigualdades económicas y las condiciones de pobreza de las comunidades receptoras.

b) Por otro lado, esta misma contribución al gasto de los hogares se traduce en efectos multiplicadores hacia el resto de la economía local, regional y nacional. Pero, ello no debe llevarnos a confundir estos efectos multiplicadores y de bienestar familiar de remesas, con los impactos que podrían tener como "palanca del desarrollo".

En el caso de las remesas de capital, desde la macroeconomía se señala que su aporte viene dado a través de su contribución al balance ahorro-inversión. Como fuente de inversión, si podemos considerar a las remesas productivas como un instrumento de crecimiento económico, que junto a otros fondos de inversión (inversión extranjera directa, inversión nacional privada, inversión pública, etc.) son la base de todo proceso de desarrollo.

Se trata no sólo de categorías distintas en cuanto a su origen, sino especialmente en relación a su función y significado económico para los países que las perciben. En efecto, no podemos confundir este impacto de las remesas de capital en el crecimiento económico con un hipotético impacto en el bienestar de la población y reducción de la pobreza, el cual está asociado a las remesas salariales. 
Con la finalidad de desmitificar a las remesas como un supuesto ingreso desencadenante del desarrollo en los países de origen, Alejandro Canales (2008) destaca que para entender el significado económico y social de las remesas en el mundo actual es fundamental ubicar a las migraciones internacionales en el contexto de los cambios estructurales de la economía mundial bajo la globalización. Bajo este último proceso se activan diversos mecanismos de inclusión y exclusión social que, a través de la precarización del empleo y otras formas de segregación social, han dado origen a un nuevo patrón de polarización y diferenciación social, que entre otras consecuencias, produce las siguientes:

a) La configuración de un régimen laboral basado en los proceso de flexibilidad y desregulación.

b) La transformación del sistema de ocupaciones, con base en la creciente segmentación y polarización de ellas y la diferenciación social que implican.

c) La conformación de grupos de población con distintos niveles de vulnerabilidad social, situación que se agrava por un contexto estructural en el que los mecanismos de negociación política y social que surgieron en la sociedad industrial, y que tomaron forma en el Estado del Bienestar, han dejado de operar para los grupos más vulnerables. Este es el mecanismo por el que en la sociedad global, se crean y recrean minorías sociales y culturales como los inmigrantes, cuya vulnerabilidad construida socialmente se traslada al mercado laboral bajo la forma de una desvalorización de su fuerza de trabajo y de sus condiciones de vida y reproducción social.

d) En el contexto anterior, las remesas son una fracción de los salarios y remuneraciones de la fuerza de trabajo migrante en esos mercados globales. Son una parte del pago que perciben los migrantes laborales, la cual por lo mismo, tiene la misma función macroeconómica que cualquier otro salario: la reproducción de la fuerza de trabajo. La peculiaridad radica en que la reproducción de la fuerza de trabajo se da en contextos binacionales y en mercados de trabajo globalizados, que se sustentan en la configuración de comunidades y familias transnacionales.

e) Las remesas son entonces la forma en que esta fracción del salario migrante se transfiere a sus familias y comunidades de origen para la reproducción social de la familia y la comunidad, como lo hace cualquier otro ingreso salarial en esas mismas comunidades (u otras comunidades). Las remesas son, sin duda, un fondo salarial, ese es su significado y función como variable macroeconómica.

f) Por otro lado, las remesas no sólo forman parte del proceso de reproducción transnacional de la fuerza de trabajo migrante, sino también de las condiciones estructurales de exclusión social y precarización laboral que enfrenta esta fuerza de trabajo. En otras palabras, al analizar el significado económico y social de las remesas no podemos hacer abstracción de este contexto global de exclusión y segregación social que caracteriza la inserción laboral de los migrantes, pues las remesas son producto directo de ese contexto global.

g) El marco estructural de exclusión y segregación social de los migrantes, es en definitiva, lo que permite diferenciar entre el carácter y significado social de las remesas que perciben los países en vías de desarrollo de aquellas que perciben las economías industrializadas del Primer Mundo.

h) Las remesas no sólo constituyen un fondo salarial, sino que corresponden a ingresos salariales de trabajadores que combinan una inserción laboral de alta vulnerabilidad y precariedad en el país receptor, sea del Norte o del Sur, con una condición de pobreza, marginación y vulnerabilidad en sus países de origen. 
Las remesas son generadas por trabajadores precarios y vulnerables, que envían a sus familiares que viven en condiciones de pobreza y marginación social. Es en este contexto que las remesas se orientan mayoritariamente al consumo familiar, contribuyendo a mantener un mínimo nivel de bienestar y que resultan insuficientes para promover un verdadero proceso de movilidad social.

Además, de la argumentación anterior que muestra los aportes y limites de las remesas familiares o remesas salarios para las comunidades y países de origen de los migrantes, todas las experiencias internacionales muestran como las migraciones internacionales y las remesas pueden ser un paliativo para la marginación y la pobreza, pero, por sí mismas ni pueden superar la pobreza, ni llevar al desarrollo económico de los países. Para ello se requiere reorientar un modelo económico mundial que arruina a las economías nacionales del Sur y lanza al mercado mundial del trabajo a sus poblaciones a buscar desesperadamente un trabajo decoroso en las economías desarrolladas principalmente (GARCÍA Z., 2006).

Se requiere reorientar el modelo económico hacia el mercado interno, sin renunciar a la articulación con el mercado mundial, fortaleciendo en especial las estrategias de desarrollo regional y sectorial. Si se pretende capitalizar los aspectos positivos de la migración internacional para el desarrollo y reducir sus impactos negativos, ello requiere de diseñar políticas de Estado sobre Desarrollo y Migración, integrales y de largo plazo, que superen la esquizofrenia de un modelo que lleva a la quiebra masiva de los productores nacionales, que aumenta la pobreza y la marginación social y el esfuerzo de algunos gobiernos latinoamericanos por buscar que los migrantes y las remesas generan desarrollo nacional (GARCÍA Z., 2008).

Las organizaciones de migrantes latinoamericanas en Estados Unidos, Europa y otras regiones potencialmente podrán actuar como un nuevo actor transnacional del desarrollo de sus países, si se cumplen, entre otras, las siguientes condiciones:

a) Políticas de Estado sobre Desarrollo y Migración que fortalezcan el mercado interno, el desarrollo regional y los diferentes sectores productivos.

b) Un cambio institucional en los tres niveles de gobierno, fortaleciendo la colaboración interinstitucional y a los gobiernos locales.

c) Un proceso permanente de organización y capacitación transnacional en las comunidades de origen destino.

\section{Referências}

CANALES, Alejandro. Remesas y Desarrollo en América Latina: Una relación en busca de teoría. 2008. Inédito.

GARCÍA ZAMORA, Rodolfo. Migración internacional, remesas y desarrollo. Los retos de las organizaciones migrantes mexicanas en Estados Unidos. Ed. Universidad Autónoma de Zacatecas, México, 2006.

GARCÍA ZAMORA, Rodolfo. Una Política Alternativa de Desarrollo y Migración para México. En: FABIENNE VENET (coord.) Hacia una Política de Estado sobre Migración en México. Miguel Ángel Porrúa-Sin Fronteras, UAZ, 2008. No prelo. 